\title{
Fear from Childbirth among Pregnant Women
}

\author{
Elsayda Hamdy Nasr ${ }^{1}$, Nada Alshehri², Mariam Awad Almutairi ${ }^{3}$, Fathia Mahmoud AbdElmenim ${ }^{4}$ \\ ${ }^{1}$ Department of Maternity, Obstetrics and Gynecological Nursing, College of Applied Medical Sciences, Prince Sattam Bin \\ Abdulaziz University, Al Kharj, Saudi Arabia \\ ${ }^{2}$ Department of Maternity and Newborn Health Nursing, College of Applied Medical Sciences, Prince Sattam Bin Abdulaziz \\ University, Al Kharj, Saudi Arabia \\ ${ }^{3}$ Nursing Administration, College of Applied Medical Sciences, Prince Sattam Bin Abdulaziz University, Al Kharj, Saudi Arabia \\ ${ }^{4}$ Department of Maternity, Obstetrics and Gynecological Nursing, Faculty of Nursing, Port Said University, Port Said, Egypt \\ Email: e.abdelhalim@psau.edu.sa
}

How to cite this paper: Nasr, E.H., Alshehri, N., Almutairi, M.A. and AbdElmenim, F.M. (2020) Fear from Childbirth among Pregnant Women. Open Access Library Journal, 7: e6427.

https://doi.org/10.4236/oalib.1106427

Received: May 14, 2020

Accepted: July 3, 2020

Published: July 6, 2020

Copyright $\odot 2020$ by author(s) and Open Access Library Inc.

This work is licensed under the Creative Commons Attribution International License (CC BY 4.0).

http://creativecommons.org/licenses/by/4.0/

\begin{abstract}
Background: Pregnancy and childbirth are a long time journey associated with physiological and psychological changes that may cause positive or negative impact on the woman's life, the baby, and her family. Fear of childbirth is one of the most factors that affect directly or indirectly on labor Process. Aim: Aim of the study was to; measure the level of fear from childbirth among pregnant women in Port Said city. Subjects and Methods: A descriptive study design was used to conduct the study at ante-natal clinics in 5 primary health care centers in Port Said city. The study subjects consisted of 200 pregnant women. Tow tools used to collect the necessary data consisted of; structured interviewee sheet, and Wijma delivery expectancy questionnaire (W-DEQ). Results: The current study revealed that about the more than half of the studied women (55.33\%) have high level of fear. A significant relation was found between fear of childbirth and sociodemographic characteristics among pregnant women. Conclusion: There was a statistically significant relationship between fear of childbirth from the studied women and their sociodemographic characteristics in the areas of educational level and their obstetric history in the areas of complications related to previous delivery. Recommendations: Designing and applying childbirth preparation classes in the third trimester of pregnancy particularly for primigravidas to promote their self-control and their self-confidence during labor leads to a more satisfactory birthing experience.
\end{abstract}

\section{Subject Areas}

Nursing

\section{Keywords}

Childbirth, Fear, Labour, Pregnancy and Pregnant Women 


\section{Introduction}

Childbirth is a universal phenomenon and a meaningful experience that has the potential to trigger developmental transitions, stress, anxiety and/or fear, which, at times, can negatively impact future childbirth experiences. Some of these psychological changes may take a short time and then relieved while others may continue until birth [1] [2].

Fear of childbirth has become a modern-day epidemic amongst pregnant women. More than ever, women are frightened about birth and what "might" go wrong. Or they are worried about not being able to cope during labor and birth. But it's important to face those fears and work out how to deal with them. Women should avoid childbirth fear to enjoy their pregnancy [3].

The fear of childbirth (FOC) is one of the most emotional causes that impact on childbirth experiences positively or negatively. It influences daily life activities and woman's confidence in coping with birth process [4] [5].

The term "fear of childbirth" (FOC) is a considerable mental, social, physiological phenomenon and anxiety disorder which impairs the women's daily functioning and wellbeing. Studies from Finland define FOC as a health issue for a pregnant woman related to a phobic fear including physical complications, nightmares and concentration problems. It's a negative perception starting in the antenatal period and continued till the birth and postpartum period [5].

\subsection{Significance of the Study}

Fear of childbirth is a common problem, and has a negative impact on the childbirth experience. This fear causes birth to take longer and mother suffers labor pain more intensely [6]. Nearly $80 \%$ of pregnant women express worries and fears in relation to their pregnancy and childbirth. However, estimations of prevalence are equivocal, presumably due to the lack of clear-cut definitions and conceptualizations of the concept to be measured. Therefore, this study is conducted to evaluate the level of fear from childbirth.

\subsection{Aim of Study}

The aim of the present study is to; measure the level of fear from childbirth among pregnant women in Port Said city.

\section{Research objectives:}

1) Determine the level of fear from childbirth.

2) Identify factors associated with fear from childbirth during pregnancy.

\section{Subject and Methods}

\subsection{Technical Design}

This design includes four main categories, study design, setting, subjects and tools for data collection.

Research design:

Descriptive design was utilized in this study. 


\section{Study setting:}

The present study was carried out in ante-natal clinics of five primary health care centers in Port-Said City which were selected randomly according to fluency rate. These were namely: Alkuwit center, Fatma Elzahraa center, El Manakh center, Omar Ebn Elkhatab center and Osman Ebn Afan center.

\section{Study sample:}

The study subjects consisted of 200 pregnant women were enrolled in this study during the period of data collection (5 months). Who attended the previously mentioned selected antenatal clinics and fulfilling the following inclusion criteria.

Inclusion criteria:

- Women at reproductive age from (20 - 35) years old.

- Both primi and multi pregnant women.

- Women at second and third trimester of pregnancy.

\section{Exclusion criteria:}

- A pregnant woman diagnosed with a psychiatric disorder.

- Women who delivered previously by cesarean section.

\section{Sampling procedure:}

Purposive sampling was used to select the subjects for the study.

\section{Tools for data collection:}

To collect data for this study Tow tools were used and tested for reliability and validity:

\section{1) A structured Interviewing Questionnaire sheet}

This tool was developed by the researcher to collect data related to: Sociodemographic characteristics, Medical history and Obstetric history.

2) The Wijma Delivery Expectancy/Experience Questionnaire (W-DEQ)

- This tool was developed by Wijma and Zar and modified by Roosevelt. It was used to measure level of fear of childbirth among pregnant women [7] [8].

- It comprised from 10-items questionnaire that measure FOC such as (how do you think you will feel in general during the birth? how you think you will feel about the place you give birth ... etc.). Items were rated on a 4-point scale ranged from 1 to 4 . The tool was translated into arabic and retranslated into English by the researcher and a language expert; and tested for its validity and reliability.

\section{Scoring system:}

The responses were scored on a 4 point likert scale from 1 to 4 , ranged from (1) to (4) with a score ranging from 10 to 40 , with higher score reflecting high level of FOC. A score equal to or lower than 20 is considered low fear, a score between 21 and 30 equates to moderate fear and a score higher than 30 represents high level of fear [9].

\subsection{Operational Design}

The study field of work was carried out through the following phases:

Preparation phase: 
It included reviewing of relevant literature, different studies and theoretical knowledge of various aspects of the problems using books, research articles, internet, periodicals and magazines.

\section{Content validity:}

It was ascertained by a jury consisting of five expertises from nursing and medical staff (obstetrics, gynecology and psychiatric department). They were requested to express their opinions and comments on the translated tool. They reviewed the tools for clarity, relevance and comprehensiveness. The tools were modified according to jury opinions such as (adding item of gestational age and change translation of some words and sentences. This phase was carried out in a period (4 months).

Content reliability:

Tools were tested for reliability using Cronbach's alpha test which The Wijma Delivery Expectancy/Experience Questionnaire was 0.920. The tools were proved to be valid and reliable with Cronbach's alpha test.

\section{Pilot study:}

The pilot study was carried out on $10 \%$ of the study subjects which represent 20 women who were excluded from the study sample. The purposes of the pilot study were to test the applicability and clarity and feasibility of the study tools and it served to estimate the time needed to complete the tools. It also helped to find out any obstacles and problems that might interfere with data collection process. Based on findings of the pilot study, certain modifications on the tools were done.

\section{Field work:}

Collection of data covered a period of five months "from the first of August 2019 to the end of December 2019". The data collection process was conducted using face to face interview technique that was on an individual basis and a private area in the center to ensure confidentiality and privacy. A number ranging from 3 - 7 of pregnant women were interviewed per day. Each interview lasted from 20 - 40 minutes depending on the responses of the interviewee. After completion, the researcher ensures that all statements included in the tools were completed. Then, pregnant women were thanked for their cooperation.

\subsection{Administrative Design}

Before starting any step in the study, an official letter was issued from the Dean of the faculty of nursing to the director of each previously mentioned study setting requesting his/her cooperation and permission to conduct the study in ante-natal clinics, after explaining the aim of the study.

\section{Ethical considerations:}

1) An official permission was taken from directors of the previously mentioned study settings to carry out the study.

2) An oral consent was obtained from the women after explaining the aim of the study.

3) The studied pregnant women were assured that the information obtained 
was confidential and used only for the purpose of the study and anonymity is guaranted.

4) The studied subjects were informed that their participation is voluntary and they had the right to with draw from the study at any time.

\subsection{Statistical Design}

Data entry and statistical analysis were done using SPSS 11.0 statistical software package. Data were presented using descriptive statistics in the form of frequencies and percentages for qualitative variables, in addition to means and standard deviations for quantitative variables.

Qualitative variables were compared using Chi-square test. Statistical significance was considered at $\mathrm{p}$-value $<0.05$ and highly statistical significance was considered at $\mathrm{p}$-value $<0.01$.

\section{Results}

Table 1 illustrates sociodemographic characteristics of the studied women. Their mean age was $27.79 \pm 5.77$, more than half of the studied women (53.5\%) were in the age group 20 to less than 30 years. The majority of them (97\%) were married. Regarding educational level more than two-fifth of the studied women (43\%) had secondary school education, while (33.5\%) had university education and above. The highest percentages of the studied women (79\%) were housewife. And $96.5 \%$ had enough economic status, and the mean crowding index was 1.6 \pm 0.6 .

Table 2 represents that $43 \%$ of the studied women had a number of pregnancy from two to four times, $49.5 \%$ of them delivered previously from one to three times and most of them (81.5\%) hadn't previous abortion.

Also, this table describes that most of the studied women (82\%) who were delivered previously had no complications compared to only $18 \%$ of them had complications, from these complications, (37.5\%) had post-partum hemorrhage. In regarding to previous place of delivery, $67.4 \%$ of the studied women delivered at private hospital and private physician clinics.

Table 3 demonstrates level of fear of childbirth among studied pregnant women, which it is noticed that the highest percentage of the studied women (55.3\%) had high level of FOC, 91\% of women were worries from birth process, about three quarter $(76 \%)$ were worried toward baby and about one third $(35.5 \%)$ of them were worries toward birthplace.

It was clear from this table that $7.75 \%$ of the studied women didn't have fear, $13.33 \%$ of them had low level of fear while, $23.6 \%$ of the studied women had moderate level of fear and more than half of them (55.33\%) reported high level of fear.

Table 4 shows that there is statistically significant relationship between fear of childbirth from the studied women and their sociodemographic characteristics in the areas of educational level and age group whereas p-value $\leq 0.05$. 
Table 1. Socio-demographic characteristics of the studied women $(n=200)$.

\begin{tabular}{|c|c|c|}
\hline \multirow{2}{*}{ Socio-demographic characteristics } & \multicolumn{2}{|c|}{ Studied Pregnant women $(n=200)$} \\
\hline & Frequency (No.) & Percentage (\%) \\
\hline \multicolumn{3}{|l|}{ Age (in years) } \\
\hline$<20$ years & 15 & 7.5 \\
\hline $20-29$ years & 107 & 53.5 \\
\hline $30-37$ years & 78 & 39 \\
\hline Mean \pm SD & \multicolumn{2}{|c|}{$27.79 \pm 5.77$} \\
\hline \multicolumn{3}{|l|}{ Marital status } \\
\hline Married & 194 & 97 \\
\hline Divorced & 4 & 2 \\
\hline Widow & 2 & 1 \\
\hline \multicolumn{3}{|l|}{ Level of education } \\
\hline Illiterate & 11 & 5.5 \\
\hline Read and write & 15 & 7.5 \\
\hline Basic education & 21 & 10.5 \\
\hline Secondary education & 86 & 43 \\
\hline University education and above & 67 & 33.5 \\
\hline \multicolumn{3}{|l|}{ Occupational status } \\
\hline Housewife & 158 & 79 \\
\hline Working & 42 & 21 \\
\hline \multicolumn{3}{|l|}{ Number of family members } \\
\hline Min - Max & \multicolumn{2}{|c|}{$2-7$} \\
\hline Mean \pm SD & \multicolumn{2}{|c|}{$3.3 \pm 1.2$} \\
\hline \multicolumn{3}{|l|}{ Number of rooms in the house } \\
\hline Min - Max & \multicolumn{2}{|c|}{$1-4$} \\
\hline Mean \pm SD & \multicolumn{2}{|c|}{$2.1 \pm 0.3$} \\
\hline \multicolumn{3}{|l|}{ Crowding index } \\
\hline Min - Max & \multicolumn{2}{|c|}{$0.7-3.5$} \\
\hline Mean \pm SD & \multicolumn{2}{|c|}{$1.6 \pm 0.6$} \\
\hline \multicolumn{3}{|l|}{ Economic status } \\
\hline Enough & 193 & 96.5 \\
\hline Not enough & 7 & 3.5 \\
\hline
\end{tabular}

Table 2. Distribution of the studied women according to their past obstetric history ( $\mathrm{n}=$ 200).

\begin{tabular}{ccc}
\hline Obstetric history & Frequency (No.) & Percent (\%) \\
\hline Gravidity & & \\
1 & 68 & 34 \\
$2-4$ & 86 & 43 \\
\hline
\end{tabular}




\section{Continued}

\begin{tabular}{|c|c|c|}
\hline$>4$ & 46 & 23 \\
\hline Mean \pm SD & \multicolumn{2}{|c|}{$2.47 \pm 1.5$} \\
\hline \multicolumn{3}{|l|}{ Parity } \\
\hline None & 68 & 34 \\
\hline $1-3$ & 99 & 49.5 \\
\hline$>4$ & 33 & 16.5 \\
\hline \multicolumn{3}{|l|}{ Number of abortion } \\
\hline None & 163 & 81.5 \\
\hline $1-3$ & 34 & 17 \\
\hline$>4$ & 3 & 1.5 \\
\hline \multicolumn{3}{|l|}{ Number of living children } \\
\hline None & 68 & 34 \\
\hline $1-3$ & 89 & 44.5 \\
\hline$>4$ & 43 & 21.5 \\
\hline Mean \pm SD & \multicolumn{2}{|c|}{$1.18 \pm 1.21$} \\
\hline \multicolumn{3}{|c|}{ Complications related to previous delivery $(n=132)$ : } \\
\hline Yes & 24 & 18 \\
\hline No & 108 & 82 \\
\hline \multicolumn{3}{|l|}{ Types of complications $(n=24)$ : } \\
\hline Postpartum pyrexia & 8 & 33.5 \\
\hline Preterm labor & 4 & 16.5 \\
\hline Fetal death & 2 & 8.5 \\
\hline Postpartum hemorrhage & 9 & 37.5 \\
\hline Uterine prolapse & 1 & 4 \\
\hline \multicolumn{3}{|l|}{ Place of previous delivery $(n=132)$ : } \\
\hline Governmental hospital & 43 & 32.6 \\
\hline Private hospital/Private physician clinic & 89 & 67.4 \\
\hline
\end{tabular}

Table 3. Fear of childbirth among the studied pregnant women $(\mathrm{n}=200)$.

\begin{tabular}{cccccccccc}
\hline \multirow{2}{*}{ Items } & \multicolumn{2}{c}{ No fear } & \multicolumn{2}{c}{ Low fear } & \multicolumn{2}{l}{ Moderate fear } & \multicolumn{2}{l}{ High fear } \\
\cline { 2 - 10 } & $\mathrm{n}$ & $\%$ & $\mathrm{n}$ & $\%$ & $\mathrm{n}$ & $\%$ & $\mathrm{n}$ & $\%$ \\
\hline Worries toward birth process & - & - & 2 & 1 & 16 & 8 & 182 & 91 \\
Worries toward self during the birth & 1 & 0.5 & 5 & 2.5 & 26 & 13 & 186 & 84 \\
Worries toward baby during the birth & 7 & 3.5 & 7 & 3.5 & 34 & 17 & 152 & 76 \\
Worries toward support people & 31 & 15.5 & 57 & 28.5 & 77 & 38.5 & 35 & 17.5 \\
Worries toward care giver & 34 & 17 & 44 & 22 & 66 & 33 & 56 & 28 \\
Worries toward birth place & 20 & 10 & 45 & 22.5 & 64 & 32 & 71 & 35.5 \\
Total percent & \multicolumn{2}{c}{7.75} & & 13.33 & & 23.6 & 55.33 \\
\hline
\end{tabular}


Table 4. Relationship between sociodemographic characteristics of the studied women and their fear from childbirth $(\mathrm{n}=200)$.

\begin{tabular}{ccc}
\hline Items & Mean Square & Test of Sig. \\
\hline Age group & 147.646 & $0.016^{*}$ \\
Educational level & 224.788 & $0.003^{*}$ \\
Occupational status & 45.524 & 0.180 \\
Economic status & 8.483 & 0.562 \\
\hline
\end{tabular}

${ }^{*}$ Statistically significant $(\mathrm{p}$-value $\leq 0.05)$.

Table 5 demonstrates that there is statistically significant relationship between fear of childbirth of the studied women and their obstetric history in the areas of complications related to previous delivery whereas $\mathrm{p}$-value $\leq 0.05$.

\section{Discussion}

Fear of childbirth (FOC) is one of the major emotions that affected by person's self-efficacy in coping with labor. Various studies revealed that low levels of self-efficacy expectancy during pregnancy among women have been shown to be associated with a high level of FOC [10]. Therefore, this study is conducted to evaluate the level of fear from childbirth among pregnant women, and identify factors associated with fear from childbirth during pregnancy.

\section{From this study it was found that:}

According to the Wijma Delievry Expectancy Questionnaire scale (W-DEQ) for measuring level of FOC among the studied women it was revealed that more than half of the studied women have high level of fear from childbirth process. This may be due to many causes such as worries from labor contraction, labor process itself, previous negative birth experience and also, there are no antenatal childbirth preparation classes applied at antenatal care centers in Egypt and subsequently, the woman don't know how to cope with labor which affects on her self-trust and confidence toward birth and causing feel more anxious and high FOC. This result is very close to that of Abd El-Aziz et al., who indicated that about half of pregnant women had high fear [9]. Also, Melender reported that most of the studied women had high level of fear related to childbirth [11].

Moreover, this result in a greement with Erkaya, Karabulutlu \& Calik, Soltani et al., Prata et al., \& Salomonsson who reported that the majority of the pregnant women had fear of childbirth [1] [12] [13] [14].

Contrarity, Matinnia, Faisal, Juni, Herjar, Moeini \& Osman at their study carried out in Iran stated that less than third of women had intense fear [15]. It is worth noting twenty percent of the women did not have any fear. Also, this finding is in disagreement with Ryding, Wirfelt \& Wängborg, who found that more than half of the pregnant women reported low level of fear and only $10 \%$ had intense level of fear [16].

Regarding high percent of fear of childbirth that is may due to many causes reported by the studied women such as: fear toward birth, fear toward loss of 
Table 5. Relationship between obstetric history of the studied women and their fear from childbirth $(\mathrm{n}=200)$.

\begin{tabular}{ccc}
\hline Items & Mean Square & Test of sig. \\
\hline Living children & 37.902 & 0.205 \\
Method of delivery & 26.450 & 0.289 \\
Complications related to previous delivery & 137.005 & $0.016^{*}$ \\
Place of previous delivery & 54.901 & 0.127 \\
\hline
\end{tabular}

${ }^{*}$ Statistically significant $(\mathrm{p}$-value $\leq 0.05)$.

control during birth, fear from becoming in danger or her baby, fear from place of delivery, fear from inability to obtain necessary care and fear from becoming alone without support during labor, fear from inability to obtain necessary care. The majority of the studied women reported fear regarding birth process, toward baby respectively while the minority of them reported low fear regarding support people and care giver. This may be explained by most of the studied women who scored high level of fear from birth process in general not being able to be confident or control in themselves at labor and they consider childbirth to be a painful, prolonged and overwhelming experience which requires an excessive amount of power and energy, WHILE, the minority of them reported low fear related to support people and care giver this may be because most of them delivered previously at private hospitals and physician clinic and became more friendly with them.

This consistent with Tanglakmankhong who listed various reasons at his study such as: afraid of giving birth is the most reason of fear among pregnant women then, fear of bleeding during delivery however, the least reasons revealed were fear of being a lone, fear of being alone without support, fear of injury and fear from hospital environment [17].

This result also agreed with Abd El-Aziz who mentioned that the most common factor of FOC was childbirth factor which women were more fearful toward birth process entirely [9]. Various reasons for fear of childbirth have been reported such as fear of pain, fear of losing control, fear of rupturing, fear of operative delivery and fear of having an impaired or stillborn infant. In addition to, young maternal age, nulli parity, pre-existing psychological issues, inadequate social support and a history of abuse or difficult obstetric procedures.

Similarly, Arfaie, Nahidi, Simbar \& Bakhtiari listed that fear of childbirth process was the first extracted category of fear of related to childbirth in our study while, healthcare quality and support were the last category and the least category for fear related to childbirth which mothers feel about safe delivery, and their wellbeing completely depends on the gynecologist, staff and the environment of the hospital [18].

On the contrast, Khorsandi, Vakilian \& Nasirsadeh in their study, found that fear of hospital environment, healthcare quality, injection and loneliness were the main factors of childbirth fears [19]. Also, Sereshi, Nahidi, Simbar, Ahmadi, 
Bakhtiari et al., on a study to found mothers' perception of quality of healthcare services stated that many participants were dissatisfied with the care provided in the hospital during pregnancy and afterwards for the following reasons: being left alone without support, lack of communication among staff and woman. These reasons are the main causes that lead to fear of childbirth [20].

This finding disagrees with Schwartz et al., who mentioned that there is a negative correlation was found between childbirth self-efficacy and medical factors [21].

For exploring factors associated with fear of childbirth at the current study this result found that there is a statistically significant relationship between sociodemographic factors and fear of childbirth in the areas of educational level and age group not at occupation or economic status which more than half of the studied women were in age between twenty to thirty age this is may be explained by that young age women not have enough experiences about labor process so, level of fear is high among them. And also, with increasing at educational level the women have knowledge about childbirth may be from reading books, searching through the internet. That improves their confidence and self-efficacy in coping with labor and leading to lack at fear level. This coincides with Elvander, Cnattingius \& Kristen who stated that women with low fear characterized by were high educated, older age. Another study by Zasloff et al. revealed that a higher education was associated with lower level of fear [22] [23].

These results are in agreement with Matinnia, Abdul Rahman, Ibrahim, Ghaleiha \& Jahangard who showed a statistically significant association between maternal age, education and fear related to childbirth [24]. Similary, this result correlated with Soltani et al., who mentioned that a negative, reversed relationship was be found between fear of childbirth and demographic factors in the areas of educational level and age [13].

However, a study by Nieminen, Stephansson \& Ryding, demonstrated that the mean scores of fear related to childbirth were not significantly associated with socio-demographic characteristics in pregnant women [25]. Also, Prataa et al., revealed that, according to the socio-demographic variables no association was found between childbirth fear and age, education level and occupational status [1]. Also, the results of present study disagreed with national research findings from Denmark and Sweden by Laursen \& Nielsen, which stated that pregnant women with fear related to childbirth were younger and unemployed, had lower levels of education [26].

The current results revealed that there is a statistically significant relationship between fear of childbirth of the studied women and their medical history in the areas of cardiac diseases in the current study. This is may be due to the pregnant woman who had cardiac disease is fearful from complications that may occur to her or her baby and her inability to provide the effort needed during labor because of her health condition. Others may be fearful from not obtaining the special care needed for her and her baby. On the same line, Erkaya et al., stated that a relationship was be found between fear of childbirth and medical history [12]. 
In regarding to obstetric factors this study revealed that less than half of the studied women had a number of pregnancy from two to three times, almost half of them delivered previously from one to two times and most of them hadn't previous abortion, around two-thirds were in third trimester (29 - 40 week) and eighteen percent of them had previous complication in labor so, it was found that there is a significant relation between obstetric history and fear of childbirth in the areas of previous complication. That's may be due to the women who had complications at previous delivery are more fearful from the future labor because of their bad experiences. This result is in congruence with Matinnia et al., who indicated that there is an evidence relationship between fear of childbirth and complications related to previous delivery [15]. Although, Erkaya et al., discussed that evidence linking of obstetric factors and fear of childbirth had been reported [12]. Also, in this respect Soltani et al., stated that a negative, reversed relationship was being found between fear of childbirth and obstetric factors in the areas of gravidity, gestational age, pregnancy complications and previous labor complications [13].

\section{Conclusions}

\section{Based on the findings of the present study, it can be concluded that:}

The more than half of the studied women had a high level of fear of childbirth. Also, the most common reasons for a high level of fear were fear from birth process, fear toward complications to her baby or herself, while the least reasons reports were fear from support people and caregivers.

Therefore, it was concluded that there was a statistically significant relationship between fear of childbirth from the studied women and their sociodemographic characteristics in the areas of educational level and their obstetric history in the areas of complications related to previous delivery.

\section{Recommendations}

Based on the results of the present study, the following recommendations were suggested:

- Designing and applying antenatal education classes as an essential component of standard antenatal care at different public antenatal centers in Port Said city.

- Designing and applying childbirth preparation classes in the third trimester of pregnancy particularly for primigravidas to promote their self-control and their self-confidence during labor that leads to a more satisfactory birthing experience.

- Further studies are recommended to explore the effect of antenatal education classes on women's fear from childbirth.

- Further studies are recommended to assess the perceptions and attitudes of healthcare providers toward applying antenatal educational classes.

- Designing and applying antenatal educational training programs into mater- 
nity and midwifery nursing undergraduate curriculum.

\section{Conflicts of Interest}

The authors declare no conflicts of interest regarding the publication of this paper.

\section{References}

[1] Prataa, A.P., Santosb, C. and Santosc, M.R. (2016) The Fear of Childbirth: A Study in the North of Portugal. 2nd International Conference on Health and Health Psychology.

[2] Oats, J.J. and Abraham, S. (2017) Llewellyn-Jones Fundamentals of Obstetrics and Gynecology E-Book.10th Edition, Elsevier, Amsterdam, Netherlands.

[3] Flores, V. (2018) Fear versus Trust: The Impact of Fear on Birth Experience and Maternal Outcome. The Journal of Prenatal and Perinatal Psychology and Health, 32, 220-241.

[4] Bahl, R., Strachan, B. and Murphy, D.J. (2004) Outcome of Subsequent Pregnancy Three Years after Previous Operative Delivery in the Second Stage of Labour: Cohort Study. BMJ, 328, 311. https://doi.org/10.1136/bmj.37942.546076.44

[5] Nilsson, C., Hessman, E., Sjoblom, H., Dencker, A., Jangsten, E., Mollberg, M. and Begley, C. (2018) Definitions, Measurements and Prevalence of Fear of Childbirth: A Systematic Review. BMC Pregnancy and Childbirth, 18, Article No. 28. https://doi.org/10.1186/s12884-018-1659-7

[6] Adams, S.S., Eberhard-Gran, M. and Eskild, A. (2012) Fear of Childbirth and Duration of Labour: A Study of 2206 Women with Intended Vaginal Delivery. British Journal of Obstetrics and Gynecology, 119, 1238-1246. https://doi.org/10.1111/j.1471-0528.2012.03433.x

[7] Wijma, K., Wijma, B. and Zar, M. (1998) Psychometric Aspects of the W-DEQ; A New Questionnaire for the Measurement of Fear of Childbirth. Journal of Obstetrics and Gynecology, 19, 84-97. https://doi.org/10.3109/01674829809048501

[8] Roosevelt, L. and Low, L.K. (2016) Exploring Fear of Childbirth in the United States through a Qualitative Assessment of the Wijma Delivery Expectancy Questionnaire. Journal of Obstetric, Gynecologic \& Neonatal Nursing, 45, 28-38. https://doi.org/10.1016/j.jogn.2015.10.005

[9] Abdel-Aziz, N.S., Mansour, S. and Hassan, F.N. (2017) Factors Associated with Fear of Childbirth: It's Effect on Women's Preference for Elective Cesarean Section. Journal of Nursing Education and Practice, 7, 136-137. https://doi.org/10.5430/jnep.v7n1p133

[10] Rondung, E., Thomtén, J. and Sundin, O. (2016) Psychological Perspectives on Fear of Childbirth. Journal of Anxiety Disorders, 44, 80-91. https://doi.org/10.1016/j.janxdis.2016.10.007

[11] Melender, R.M. (2002) Experiences of Fears Associated with Pregnancy and Childbirth: A Study of 329 Pregnant Women. Birth, 29, 101-111. https://doi.org/10.1046/j.1523-536X.2002.00170.x

[12] Erkaya, R., Karabulutlu, O. and Çalık, K.Y. (2017) Defining Childbirth Fear and Anxiety Levels in Pregnant Women. Procedia-Social and Behavioral Sciences, 237, 1045-1052. https://doi.org/10.1016/j.sbspro.2017.02.151

[13] Soltani, F., Eskandari, Z., Khodakarami, B., Parsa, P. and Roshanaei, G. (2017) Fac- 
tors Contributing to Fear of Childbirth among Pregnant Women in Hamadan (Iran) in 2016. Electronic Physician, 9, 4725-4731. https://doi.org/10.19082/4725

[14] Salomonsson, B., Berterö, C. and Alehagen, S. (2013) Self-Efficacy in Pregnant Women with Severe Fear of Childbirth. Journal of Obstetric, Gynecologic \& Neonatal Nursing, 42, 191-202. https://doi.org/10.1111/1552-6909.12024

[15] Matinnia, N., Faisal, I., Juni, M.H., Herjar, A.R., Moeini, B. and Osman, Z.J. (2015) Fears Related to Pregnancy and Childbirth among Primigravidae Who Requested Caesarean Versus Vaginal Delivery in Iran. Maternal and Child Health Journal, 19, 1121-1130. https://doi.org/10.1007/s10995-014-1610-0

[16] Ryding, E.L., Wirfelt, E., Wängborg, I.B., Sjögren, B. and Edman, G. (2007) Personality and Fear of Childbirth. Acta Obstetricia et Gynecologica Scandinavica, 86, 814-820. https://doi.org/10.1080/00016340701415079

[17] Tanglakmankhong, K. (2010) Childbirth Expectations and Childbirth Experiences among Thai Pregnant Women. Oregon Health \& Science University, Oregon.

[18] Arfaie, K., Nahidi, F., Simbar, M. and Bakhtiari, M. (2017) The Role of Fear of Childbirth in Pregnancy Related Anxiety in Iranian Women: A Qualitative Research. Electronic Physician, 9, 3733-3740. https://doi.org/10.19082/3733

[19] Khorsandi, M., Vakilian, K. and Nasirsadeh, M. (2014) Investigating Different Factors of fear in Normal Delivery among Pregnant Woman, in Arak-A Cross Sectional Study. Journal of Fasa Medical Science, 4, 161-167.

[20] Sereshti, M., Nahidi, F., Simbar, M., Ahmadi, F., Bakhtiari, M. and Zayeri, F. (2016) Mothers' Perception of Quality of Services from Health Centers after Perinatal Loss. Electronic Physician, 8, 2006-2017. https://doi.org/10.19082/2006

[21] Schwartz, L., Toohill, J., Creedy, D.K., Baird, K., Gamble, J. and Fenwick, J. (2015) Factors Associated with Childbirth Self-Efficacy in Australian Childbearing Women. BMC Pregnancy and Childbirth, 15, Article No. 29. https://doi.org/10.1186/s12884-015-0465-8

[22] Elvander, C., Cnattingius, S. and Kjerulff, K.H. (2013) Birth Experience in Women with Low, Intermediate or High Levels of Fear: Findings from the First Baby Study. Birth, 40, 289-296. https://doi.org/10.1111/birt.12065

[23] Zasloff, E., Schytt, E. and Waldenstrom, U. (2007) First Time Mothers' Pregnancy and Birth Experiences Varying by Age. Acta Obstetricia et Gynecologica Scandinavica, 86, 1328-1336. https://doi.org/10.1080/00016340701657209

[24] Matinnia, N., Rahman, H.A., Ibrahim, F., Ghaleiha, A., Akhtari-Zavare, M., Jahangard, L. and Ghaleiha, A. (2016) Predictors of Fear Related to Childbirth among Iranian Primigravidae. Global Journal of Health Science, 9, 266-275. https://doi.org/10.5539/gjhs.v9n3p266

[25] Nieminen, K., Stephansson, O. and Ryding, E.L. (2009) Women's Fear of Childbirth and Preference for Cesarean Section-A Cross-Sectional Study at Various Stages of Pregnancy in Sweden. Acta Obstetricia et Gynecologica Scandinavica, 88, 807-813. https://doi.org/10.1080/00016340902998436

[26] Laursen, B. and Nielsen, J.W. (2008) Influence of Sociodemographic Factors on the Risk of Unintentional Childhood Home Injuries. European Journal of Public Health, 18, 366-370. https://doi.org/10.1093/eurpub/ckn034 